\title{
Preserving Digital Materials. 3rd edition. By Ross Harvey and Jaye Weatherburn.
} Lanham, MD: Rowman and Littlefield, 2018. 249 pp. Index. Softcover. \$50.00.

A key responsibility of archivists is the preservation of unique materials. ${ }^{1}$ However, those professionals interested in tackling digital preservation may find themselves paralyzed into inaction as they confront a sprawling and complex field. In the third edition of Preserving Digital Materials, Ross Harvey (adjunct professor of information management at Monash University) and Jaye Weatherburn (digital preservation officer at the University of Melbourne) offer their beleaguered colleagues a well-organized text that illuminates key digital preservation discussions and topics. Harvey and Weatherburn draw upon a myriad of sources - including works published by key figures and organizations in the library and information science field, such as the Council on Library and Information Resources - to answer four pivotal questions: 1) "Why do we preserve digital materials?" 2) "What digital materials are we preserving?" 3) "How do we preserve digital materials?" and 4) "How do we manage digital preservation?" (pp. vii-ix).

Harvey and Weatherburn divide their book into four sections to address these queries (see pp. xxiii-xxv for summaries of each section and chapter). The first section lays the foundation for an intelligible discussion of more advanced digital preservation topics by introducing the field and defining key concepts such as data, digitalobject, access, authenticity, and digital preservation (pp. xxiii, 9, 13). Here, the authors argue that the advent of digital content has warranted a change in preservation tactics and thought, particularly with regard to stakeholders, and explain the necessity of preserving digital materials by describing the costs of inaction. Over the course of the book's second section, Harvey and Weatherburn address key topics relating to digital objects and their preservation, including digital preservation issues, different kinds of storage (including cloud-based storage), and elements that influence digital appraisal such as "context and community" (p. 63). This section also addresses valuable preservation standards and concepts, such as the OAIS Reference Model; the value of metadata, especially preservation metadata; and authenticity, including related research efforts like the InterPARES (International Research on Permanent Authentic Records in Electronic Systems) Project (pp. 89-90). The third section focuses on digital preservation implementation, including important digital preservation components such as policies, procedures, and guidelines (pp. 104-5); specific tactics, such as migration, emulation, and various "non-solutions" like creating analog surrogates of digital content (p. 106); and more advanced practices such as web archiving and e-mail preservation. The final section serves as a conclusion in which the authors highlight numerous digital preservation efforts and organizations (e.g., the Digital Preservation Coalition) and reflect on challenges and opportunities that practitioners will have to consider in the future, such as funding issues, expanding digital preservation knowledge to even more professionals, and considering options such as "parsimonious preservation" (p. 209).

Addressing both digital curation and preservation, Preserving Digital Materials possesses numerous strengths. Harvey and Weatherburn structured their work to facilitate their readers' knowledge development, as evidenced by the book's logical ordering. For 
example, definitions of key terms precede discussions of specific preservation tactics like migration or emulation (p. xxiii). Additionally, Harvey and Weatherburn offer logical examples to support their arguments, as exemplified by their frequent use of the Domesday Project to highlight digital archaeology and the perils of digital obsolescence (pp. 120-21). Finally, the authors generally avoid discussing esoteric theories in the body of their work - such as Sue McKemmish and Frank Upward's records continuum model-although such concepts do appear in the authors' references so that readers can investigate these ideas at their leisure. ${ }^{2}$ These tactics ensure that Preserving Digital Materials appeals to a variety of audiences-an important quality, given that one of Harvey and Weatherburn's frequent comments concerns the importance of "expanding the pool of [digital preservation] stakeholders" (p. 22).

Preserving Digital Materials is also remarkably comprehensive in scope. In addition to addressing topics familiar to North American readers, Harvey and Weatherburn also include examples from Europe and elsewhere, like the German digital preservation network "nestor" and the Australian National Data Service (pp. 188-89). Although the authors emphasize their text is not intended to be a "practically oriented how-to manual" (p. xix), they do occasionally highlight various digital archiving tools, such as the e-mail archiving tool ePADD or the web archiving tool Webrecorder (pp. 155, 159). This allows them to demonstrate to their readers how one can work with these more unique digital records. Finally, the robust, topically organized bibliography of resources at the conclusion of Preserving Digital Materials - in concert with the authors' general reliance on scholarship by well-known LIS figures such as Nancy McGovern, Jackie Dooley, Paul Conway, and Jeremy Leighton John—-reassure readers that this text is authoritative.

Preserving Digital Materials is not without its flaws or gaps, however. The authors themselves note in their introduction that their book addresses a largely "Western view of preservation" (p. xix) - meaning that the scholarly and/or practical experiences of non-Western archivists and librarians remain absent and unable to inform readers. Additionally, Harvey and Weatherburn do not always delve deeply into relevant topics, as evidenced by their brief discussion of digital forensics (pp. 121-23) versus their more robust discussion of research data curation (pp. 143-48). In rare cases, they do not provide definitions for key terms, such as disk image, which runs the risk of confusing readers. ${ }^{3}$ However, arguably the biggest shortcoming of Preserving Digital Materials is the authors' heavy reliance on quotations from their source materials. This issue, in concert with the authors' valid efforts to provide multiple perspectives on various topics, often diminishes their own voice to the detriment of the reader. For example, in their discussion concerning "How Much Data Have We Lost?” (p. 25), they seemingly oppose alarmism while simultaneously noting that "the small number of specific examples of data that have been located indicates how great the problem of loss or compromise of digital materials probably is" (p. 27). This provokes some amount of confusion from the reader that could, in turn, detract from the authors' principal purpose of answering key questions and providing both the knowledge and confidence for readers to tackle digital preservation concerns. 
Overall, though, these problems do not prevent Preserving Digital Materials from serving as a useful text for audiences from all walks of life who deal with digital resources. With its vast scope and rich detail, readers will no doubt find this book to be an important resource, regardless of whether their interest in digital preservation is personal, academic, professional, or a combination of all three.

Steven Gentry Archives Technician St. Mary's College of Maryland

\section{NOTES}

1. Richard Pearce-Moses, A Glossary of Archival and Records Terminology (Chicago: Society of American Archivists, 2005), 33, http://files.archivists.org/pubs/free/SAA-Glossary-2005.pdf.

2. Sue McKemmish, "Placing Records Continuum Theory and Practice," Archival Science 1, no. 4 (2001): 333-59.

3. Computer Security Resource Center Glossary, s.v. "disk image," National Institute of Standards and Technology, https://csrc.nist.gov/glossary/term/Disk-image. 